\title{
Enfrentamento da AIDS entre mulheres infectadas em Fortaleza - $\mathbf{C E}^{*}$
}

\author{
HOW INFECTED WOMEN IN FORTALEZA-CE COPE WITH AIDS
}

\section{ENFRENTAMENTO DEL SIDA ENTRE MUJERES INFECTADAS EN FORTALEZA-CE}

\author{
Carolina Maria de Lima Carvalho', Marli Teresinha Gimeniz Galvão²
}

\section{RESUMO}

Este estudo objetivou apreender como as mulheres com aids enfrentam o cotidiano após o conhecimento do seu diagnóstico. Trata-se de estudo exploratório, descritivo, com abordagem qualitativa, utilizando a História Oral Temática para coleta e análise de dados. Foram entrevistadas dez muIheres com aids em um Hospital de referência em Fortaleza-CE, de dezembro de 2004 a março de 2005. Para coleta de dados utilizou-se roteiro semi-estruturado, cujos dados foram categorizados. Os resultados revelam diferentes formas de enfrentamentos relacionados à fragilidade da descoberta do diagnóstico, à necessidade de ocultar a infecção decorrente da discriminação e preconceito que vivenciam, e à constante percepção da morte; além de emitirem sentimentos, como vergonha, preocupação com a família, abandono, solidão, tristeza, medo da morte, ansiedade. Concluiu-se que, apesar de mais de duas décadas de epidemia, fica evidente as dificuldades enfrentadas pelas mulheres ao vivenciarem sua infecção.

\section{DESCRITORES}

Síndrome de Imunodeficiência Adquirida. Infecções por HIV.

Mulheres.

Preconceito.

Enfermagem.

\begin{abstract}
The objective of this study was to learn how women with Aids cope with daily living after receiving their diagnosis. It is an exploratory, descriptive study with a qualitative approach based on thematic oral history for data collection and analysis. Ten women with Aids were interviewed at a reference hospital in Fortaleza, State of Ceará, from December 2004 to March 2005. A semi-structured questionnaire was used for data collection. The results revealed different ways of coping, related to the fragility of the discovery of the diagnosis, to the need to hide the infection due to the discrimination and prejudice faced by the victims, and to the constant perception of death. In addition, the women expressed feelings such as shame, concern about family, abandonment, solitude, sadness, fear and anxiety. The authors conclude that, two decades after the epidemic broke out, women still face evident difficulties when they experience their infection.
\end{abstract}

\section{KEY WORDS}

Acquired Immunodeficiency Syndrome. HIV infections.

Women.

Prejudice.

Nursing

\section{RESUMEN}

Este estudio tuvo como objetivo aprender cómo las mujeres con sida enfrentan el cotidiano después de conocer su diagnóstico. Se trata de un estudio exploratorio, descriptivo, con abordaje cualitativo, utilizando la Historia Oral Temática para la recolección y el análisis de los datos. Fueron entrevistadas diez mujeres con sida en un Hospital de referencia en Fortaleza-CE, de diciembre del 2004 a marzo del 2005. Para la recolección de los datos se utilizó una guía semi-estructurada, cuyos datos fueron categorizados. Los resultados revelan diferentes formas de enfrentamiento relacionados a la fragilidad del descubrimiento del diagnóstico, a la necesidad de ocultar la infección consecuente de la discriminación y prejuicios que vivencian, y a la constante percepción de la muerte; además de reflejar sentimientos, como vergüenza, preocupación con la familia, abandono, soledad, tristeza, miedo a la muerte, ansiedad. Se concluyó que, pese haber pasado más de dos décadas de epidemia, queda evidente las dificultades enfrentadas por las mujeres al vivenciar su infección.

\section{DESCRIPTORES}

Sindrome de Inmunodeficiencia

Adquirida.

Infecciones por VIH.

Mujeres.

Prejuicio.

Enfermería.

\footnotetext{
* Extraído da dissertação "Mulheres vivenciando o estigma decorrente da aids", Universidade Federal do Ceará, $2005 .{ }^{1}$ Enfermeira. Mestre em Enfermagem. Professora Substituta do Departamento de Enfermagem, Universidade Federal do Ceará (UFC). Fortaleza, CE, Brasil. Integrante do Grupo de Pesquisa AutoAjuda para o Cuidado de Enfermagem - CNPq. karollina@click21.com.br ${ }^{2}$ Enfermeira. Professora Doutora do Curso de Pós-Graduação em Enfermagem, Universidade Federal do Ceará (UFC).Fortaleza, CE, Brasil. marli@ufc.br
} 


\section{INTRODUÇÃO}

Há mais de duas décadas o mundo convive com a epidemia de aids. Com o passar dos anos, muito se descobriu sobre formas de transmissão, terapias medicamentosas mais eficazes, marcadores laboratoriais mais precisos, imunogenicidade, entretanto, ainda é evidente o preconceito que as pessoas sofrem após a realização do diagnóstico.

A Organização Mundial de Saúde aponta que as pessoas que vivem com HIV/aids enfrentam um conjunto de problemas específicos. Muitos pacientes têm que conviver com o estigma e a discriminação, incluindo os países com uma alta prevalência onde o HIV atinge um grande número de indivíduos da população. As pessoas são reticentes a falar de seu estado de infectado, o qual contribui para aumentar seus sentimentos de isolamento ${ }^{(1)}$.

Abordar a aids entre mulheres não pode ser simples, visto que discutir o assunto exige levantar questões relacionadas ao casamento, à maternidade, à sexualidade, à relação de gênero e outros aspectos íntimos da natureza feminina, indissoluvelmente associadas à prevenção do $\mathrm{HIV}^{(2)}$.

O diagnóstico é sempre um choque para a mulher. Acarreta um trauma de natureza física, emocional e social. A forma como a mulher vai reagir às mudanças geradas decorrente da doença vai depender de diversos fatores, dentre eles, ou de sua personalidade e de seu contexto sócio-familiar ${ }^{(3)}$.

Diante da descoberta do diagnóstico de aids, a mulher experimenta sentimentos de incerteza e insegurança, conduzindo a viver um momento de crise. Nesta perspectiva, desenvolveu-se o presente estudo cujo objetivo é apreender como as mulheres com aids enfrentam o cotidiano após o conhecimento do seu diagnóstico.

\section{MÉTODO}

Tratou-se de um estudo exploratório, de caráter descritivo, com abordagem qualitativa. A pesquisa qualitativa combina as naturezas científica e artística da enfermagem para aumentar a compreensão da experiência de saúde humana ${ }^{(4)}$, estudam fenômenos em seus cenários naturais, tentando compreender, ou interpretar, em termos dos significados que as pessoas trazem para eles ${ }^{(4-5)}$. Assim, baseia-se na premissa de que os conhecimentos sobre os indivíduos só são possíveis com a descrição da experiência humana, tal como ela é vivida e tal como ela é definida por seus próprios atores ${ }^{(6)}$.

Como modalidade de pesquisa utilizou-se a História Oral Temática, que faz o uso da documentação oral e as fontes escritas são cabíveis, podendo-se utilizar um questionário com questões capazes de atender ao que se busca $^{(7-8)}$.

O estudo foi desenvolvido em uma unidade de internação do Hospital de referência para Doenças Infecciosas de Fortaleza-CE, de dezembro de 2004 a março de 2005. Participaram dez mulheres com diagnóstico prévio de aids com idade superior a 18 anos e que aceitaram livremente a participar da pesquisa. Determinou-se o tamanho da amostra do estudo quando se alcançou a saturação das informações. Um estudo(8) orienta que o limite de entrevistas remete à utilidade e ao aproveitamento delas. Na medida em que os argumentos começam a ficar repetidos, deve-se parar.

Para coleta de dados utilizou-se um roteiro semi-estruturado para nortear as entrevistas, que foram gravadas em ambiente privativo sem a interferência externa e em horários de pouco fluxo nas enfermarias. O roteiro contemplava perguntas de caráter subjetivo, onde se levantou dados relativos à identificação da mulher e questões relacionadas as intercorrências ocorridas após a descoberta da infecção pelo HIV/aids, focalizando-se principalmente como ocorria o enfrentamento da doença.

Para análise de dados houve o processo de transformação do relato oral para um texto escrito, utilizando-se três etapas:

1) Transcrição que é a passagem da gravação oral para o escrito;

2) Textualização, feita a partir da definição de palavras-chave que servem para mostrar a incidência das ênfases dadas em algumas situações, e

3) Transcriação quando se recria o texto em sua plenitude, correspondendo à finalização do texto, a sua versão pronta $^{(8)}$.

Para o tratamento dos dados utilizou-se a análise de conteúdo ${ }^{(9)}$, compondo-se de três fases:

1) Pré-análise que é a organização e sistematização das idéias;

2) Exploração do material, correspondente a transformação sistemática dos dados brutos do texto, por recorte, agregação e enumeração, visando atingir uma representação do conteúdo ou da sua expressão e, conseqüentemente, a compreensão do texto e

3) Tratamento dos resultados, a inferência e a interpretação. Foram interpretados os depoimentos e categorizados por inferência de conteúdos semelhantes.

A pesquisa foi desenvolvida após a autorização do Comitê de Ética em Pesquisa do Hospital de acordo com a resolução no 196/1996 (sob n. 033/2004), que regulamenta a pesquisa com seres humanos ${ }^{(10)}$. Para preservar o anonimato, as mulheres receberam pseudônimos de flores. 


\section{RESULTADOS E DISCUSSÃO}

As dez mulheres estavam internadas com diagnóstico de aids, com idade entre 20 e 50 anos e informavam poucos anos de estudos. Quanto a situação conjugal, quatro diziam-se solteiras, entre as demais, três eram casadas, duas separadas e uma viúva. Seis tinham emprego regular e as demais se ocupavam de tarefas do lar. Viviam com renda de um salário mínimo (o valor do salário mínimo vigente na época do estudo era $R \$ 260,00$, equivalente a aproximadamente US\$ 99.00).

A maioria descobriu-se infectada pelo HIV em decorrência da doença do parceiro. As mulheres ao contarem a sua história de vida, relataram todo o dilema da convivência com a aids a partir do diagnóstico.

Para a organização dos resultados, os dados foram distribuídos a partir da história oral temática em categorias:

1) Fragilidade diante da descoberta da doença;

2) Ocultando o diagnóstico;

3) Convivendo com a doença e

4) Iminência da morte.

Considerando os conteúdos relacionados ao enfrentamento do diagnóstico, prevaleceram diversos sentimentos, envolvendo a dor e o medo da descoberta do diagnóstico, a vergonha dentro da família, o silêncio das pessoas e o pensamento sobre a morte.

\section{Fragilidade diante da descoberta da doença}

Desde seu início, a epidemia vem acompanhada de situações de discriminação, constituindo um dos aspectos desafiantes, por ser doença inicialmente vinculada ao homossexualismo e a promiscuidade, tem conduzido os portadores a vivenciarem diferentes processos de enfrentamento diante do diagnóstico ${ }^{(11)}$.

O diagnóstico da aids representa um evento catastrófico, por estar associado a uma evolução clínica de rápida deterioração, além de não se dispor de qualquer tratamento curativo e de apresentar um prognóstico extremamente ruim ${ }^{(11-12)}$.

O fato de saber ser portadora de doença letal gera uma diversidade de sentimentos angustiantes, como o medo, a vergonha, a ansiedade e a depressão. E ainda associados a todos esses sentimentos, vivenciam o estigma, o preconceito, o isolamento e muitas vezes o abandono. Situações observadas nos depoimentos das mulheres estudadas.

As mulheres chegaram ao diagnóstico desde uma variedade de circunstâncias. Por solicitação médica decorrente de sintomatologia manifesta (doenças oportunistas) ou diante do diagnóstico do companheiro. O conheci- mento da contaminação foi devastador para a mulher, principalmente entre aquelas que a transmissão ocorreu por relações sexuais com parceiro fixo e único, predominando sentimento de traição. Para elas o fato de manterem um relacionamento estável significava distância do risco de transmissão.

Diferentes sentimentos assolam as mulheres, conforme se evidencia nas citações decorrentes de suas histórias como se segue:

\begin{abstract}
...descobri o diagnóstico através do meu marido que adoeceu... me senti arrasada, na hora deu vontade de morrer, passou mil coisas pela minha cabeça, achava que naquele dia eu ia dormir e não ia acordar viva... é tanta coisa....(Bromélia).
\end{abstract}

\begin{abstract}
...descobri que estava infectada após a confirmação do diagnóstico do meu marido ele estava emagrecendo muito rapidamente e encontrava-se muito debilitado... foi difícil descobrir-se infectada, tive medo do preconceito, e por ser a aids uma doença perigosa e violenta, pensei que ia morrer logo...(Arizema).
\end{abstract}

Depreende-se pelas falas acima um desabafo e a iminência do sentimento de morte. Situação declarada em estudo desenvolvido destaca que o momento do conhecimento do diagnóstico de infecção pelo HIV constitui-se dos mais críticos e, sobretudo, negligenciado de intervenção psicossocial pelos profissionais da saúde ${ }^{(13)}$.

Os fenômenos apreendidos a partir das histórias de vida das entrevistadas revelam os sentimentos vivenciados frente à descoberta do acontecimento. Essa revelação se faz por meio das seguintes expressões:

\begin{abstract}
...foi horrível quando eu descobri o diagnóstico, entrei em depressão ... fiquei arrasada...eu já tinha ouvido falar na doença, porém nunca pensei que um dia eu pudesse ser contaminada. Descobri por causa do Sarcoma, fui internada e solicitaram o teste do HIV...o resultado positivo foi uma bomba, o mundo desabou....(Jasmim).

... no instante do diagnóstico vi o mundo desabar na minha frente e só pensei em morrer, por duas vezes tentei o suicídio, queria realmente me matar, porque a doença não tem cura mesmo...então a morte seria a solução...(Hortência).
\end{abstract}

Eu já tinha ouvido falar sobre HIV/aids, porém nunca imaginei... jamais passou pela minha cabeça a possibilidade de um dia me ver acometida dessa doença... não acredito e não aceito a doença. Descobrir o diagnóstico foi horrível, era como se o mundo tivesse acabado ali naquele momento... tenho medo, vergonha ...(Margarida).

Muitas foram as situações vivenciadas e os sentimentos expressos a partir da descoberta do diagnóstico. Percebeu-se sinceridade e veracidade nos depoimentos, resultando assim, diversas implicações como: dificuldade em aceitar e acreditar no diagnóstico; tentativa de suicídio; depressão que acompanhou a ocasião e isolamento e 
vergonha. A descoberta da soropositividade foi relatada como um dos momentos críticos, surgindo medos, situações de rejeição e negligência, sendo particularmente uma experiência dolorosa para elas.

A confirmação do diagnóstico é a instituição de uma identidade que gera novos comportamentos e sentimentos frente à vida. A aids é uma doença relacionada ao desvio, à sexualidade e a morte, cuja revelação para a sociedade trás sérios problemas para o cotidiano dessas mulheres ${ }^{(14)}$.

Para essas mulheres o diagnóstico de soropositividade trouxe consigo uma profunda ruptura, desordem, desorientação. O futuro, naquele momento, deixou de existir destruindo também o presente delas, trazendo ainda uma série de conseqüências para a vida dessas mulheres.

A aids, quando diagnosticada, assola seu portador de dúvidas e incertezas. Dúvidas a respeito de desenvolvê-la ou não e do quão doloroso e inevitável poderá ser o progresso da doença, fazendo-o conviver permanentemente com a certeza de morte breve ${ }^{(15)}$.

\section{Ocultando o diagnóstico}

Por sua associação inicial com comportamentos socialmente desviantes e, por isso mesmo, sujeitos à condenação da sociedade, a aquisição do vírus trouxe ainda para seus portadores o problema adicional de tornar pública sua condição de infectado(15).

Assim, um dos dilemas vivido pelas mulheres é a revelação do diagnóstico. Essa descoberta está associada às dificuldades que enfrentará em decorrência da sua infecção. Elas são levadas a ocultar o seu diagnóstico devido ao medo de serem estigmatizadas, rejeitadas, ou seja, vítimas do preconceito das pessoas.

O HIV/aids foi construído diante de conceitos de perversidade e de misérias humanas, como as questões do homossexualismo masculino, promiscuidade feminina e uso de drogas. Essas questões foram suficientes para conduzir os acometidos com a doença a uma sensação de culpa e vitimização de situações não vivenciadas por eles. Assim, a infecção constitui para a sociedade, um significado carregado de sentidos morais(16).

O medo do julgamento e da exclusão social desencorajava a declaração de responsabilidade pessoal pela ocorrência do infortúnio, criando o portador clandestino. Na condição de clandestinidade, pelo menos por algum tempo, o paciente não sofre perdas, seja do parceiro afetivo, do emprego, dos amigos, seja da família ${ }^{(17)}$.

No presente estudo, as entrevistadas referiram o medo de revelar o diagnóstico de soropositividade. Preferem que as pessoas não tomem conhecimento do diagnóstico, pois, se souberem vão olhá-las diferente e tratá-las com indiferença, inclusive a própria família é excluída desse conhecimento. Pode-se observar essas situações de sigilo quanto ao diagnóstico nos trechos das histórias a seguir:
..., tenho até medo de que as pessoas perguntem onde estou internada, não posso revelar para que não saibam do meu diagnóstico...os patrões principalmente, pois se souberem não me contratam mais para os serviço. ... (Arisema).

...só quem sabe da minha soropositividade é a minha mãe e minha a irmã, o restante da família não tem o conhecimento do fato...é difícil esconder, mas prefiro por causa do preconceito, pois sei que ainda existe muito preconceito...(Jasmim).

...só recebo apóio da minha mãe, que está sempre do meu lado, me apóia mesmo. Das outras pessoas só percebo rejeição e preconceitos, como as colegas da rua que me evitam e sumiram todas...(Hortência).

...no local onde eu moro ninguém sabe do meu diagnóstico e eu prefiro que seja assim, só quem tem conhecimento da minha doença é a família, e que ainda assim me critica, encontro o preconceito ....(Violeta).

...quando preciso desabafar só conto com a minha mãe pra falar o que sinto, os vizinhos e conhecidos não ... (Rosa).

Evidencia-se pelas falas a omissão da declaração do diagnóstico provocada pelo medo de vivenciar preconceito e discriminação por parte das pessoas com quem convivem. O temor de serem identificadas persegue essas mulheres o tempo todo. A preferência pelo ocultamento do diagnóstico foi relatada por unanimidade nas histórias. Ficou claro nas falas que essa tentativa de omissão do diagnóstico é devido à estigmatização e ao preconceito que acompanham o HIV/aids.

Fato também evidenciado em estudo realizado com adolescentes soropositivos, que referiram que mantêm em segredo a sua condição, afastando-se das pessoas por medo da rejeição, da discriminação e do preconceito por parte dos que estão ao seu redor ${ }^{(18)}$.

Revelar o diagnóstico implica em submeter-se a vivências de polaridades divergentes, ou seja: solidariedade, apoio, compreensão, atribuição de críticas negativas, estigmas, discriminação social e rompimentos de relacionamentos ${ }^{(19)}$.

Assim se percebe a dura realidade que essas mulheres enfrentam diante da revelação do diagnóstico, e que a preferência manifestada pelo sigilo do diagnóstico é devido aos estigmas que a aids carrega consigo e ao tão previsível medo do preconceito, do isolamento, da rejeição, enfim, da carga pesada que essa doença trás consigo.

Há descrição afirmando que a preocupação com o sigilo sobre a infecção compromete a qualidade de vida do paciente. A revelação de estar infectado, muitas vezes é auto-imposta pelo medo que o portador ou doente, tem de, ao tornar conhecido seu diagnóstico, ficar sujeito a preconceitos e estigmatização(20). 
A mentira e a omissão servem, muitas vezes, como importantes estratégias de enfrentamento, especialmente na fase inicial de convívio com a soropositividade, para evitar situações de estigmatização. É um modo de manter a privacidade e o sigilo, evitando estabelecer conflitos ${ }^{(11)}$.

Pesquisadores são categóricos referindo que grande parte dos indivíduos soropositivos esconde o fato de estarem contaminados pelo maior tempo e da melhor maneira possível, ingressando na clandestinidade quanto à sua condição. Com isso, tentam driblar o isolamento social ao qual poderiam estar submetidos, inevitavelmente, na maioria das vezes, caso se declarassem portadores do $\mathrm{HIV}^{(17)}$.

A omissão do diagnóstico é também estendida muitas vezes a própria família, pelo receio de como os familiares vão reagir e encarar a nova situação. Como também pelo medo da rejeição e discriminação dos parentes.

Ainda é marcante na vida dos portadores de HIV/aids a necessidade constante de ocultar o diagnóstico da infecção à sociedade, sendo, portanto, múltiplas as causas associadas a essa atitude, como: medo, vergonha, receio de serem estigmatizadas e vítimas dos preconceitos atribuídos à doença. Fato que se confirma no presente estudo através dos depoimentos. Essas situações foram corroboradas com diversos estudos que abordam a temática HIV/aids aqui apresentados.

\section{Convivendo com a doença}

A aids surge de forma espantosa, revelando e trazendo a discussão do que antes era vivido na clandestinidade, como a sexualidade e a morte.

Muitas são as dificuldades enfrentadas por essas mulheres durante a convivência com a doença, e estes têm repercussões em sua qualidade de vida. Sentimentos como medo, vergonha, humilhação, preocupação e receio de adoecer são evidentes nos relatos.

Pode-se observar esses sentimentos nos depoimentos a seguir:

\footnotetext{
...eu já tinha ouvido falar em HIV/Aids, porém eu nunca imaginei, nunca passou pela minha cabeça que um dia eu podia ter essa doença, já tenho essa doença há um ano mas ainda não acredito e não aceito... tenho medo, vergonha, quase ninguém sabe do meu diagnóstico porque tenho vergonha, as pessoas vão me olhar diferente... (Margarida).

...é horrível conviver com essa infecção, é muito difícil e eu não suporto mais essa situação. Somente a minha mãe me apóia, percebo rejeição e preconceito através das outras pessoas, como as colegas de rua que me evitam...(Hortência).

....as situações do dia-a-dia me deixam bastante chateada e desgostosa, as pessoas me discriminam, tem nojo de chegar próximo de mim, assim fico com vergonha...depois que descobri o HIV, fiquei mais triste, vivo por viver, perdi o gosto pela vida...(Bromélia).
}

...fico constrangida com os comentários das pessoas, o preconceito é muito presente e está em toda parte...minha vida mudou muito depois da descoberta do HIV... fiquei mais triste, desanimada, não tenho mais esperança de viver uma vida alegre...(Papoula).

Esses depoimentos se mostram carregados de sentimentos como o medo, a vergonha, a rejeição, o preconceito, a tristeza, a falta de esperança e, essas mulheres expressam por trás desses sentimentos, a dificuldade e a problemática de conviver com HIV/aids, uma doença marcada por estigmas e discriminações. Elas descrevem o descaso e o abandono de pessoas de seu convívio, ou seja, as pessoas, que nesse momento tão difícil de enfrentar, deveriam estar ao seu lado, ajudando-as a vencer ao invés de negar-se apóia-las.

Ao viver com HIV as mulheres deparam-se com situações de discriminação, segregação, falta de recursos sociais e financeiros, ruptura nas relações afetivas e problemas com a sexualidade. Diante desse panorama, viver e enfrentar a doença torna-se cada vez mais problemático e, como conseqüência, a qualidade de vida pode ser comprometida $^{(20)}$.

A dificuldade de enfrentamento da doença acaba gerando entre os doentes um prejuízo ao próprio tratamento. Essa situação ocorre em detrimento da inabilidade do paciente para enfrentar as diversas situações de estresse causadas após o diagnóstico da infecção pelo $\mathrm{HIV}^{(15)}$. Estratégias mais adequadas à luta contra a síndrome podem viabilizar melhor qualidade de vida entre os acometidos ${ }^{(15)}$.

O enfrentamento adequado de uma doença significa adaptação à nova situação. Nos estudos relacionados ao HIV/aids, geralmente os pacientes têm dificuldades de adaptação à nova situação de portador do vírus. $\mathrm{O}$ tipo de reação da pessoa ao HIV indica sua (in)capacidade de luta contra o mesmo, sendo visivelmente mais forte aquele que consegue exercer suas atividades rotineiras, apesar da existência do vírus no seu organismo, e inevitavelmente mais fraco e passivo aquele se deixa levar pela progressão inexorável da doença ${ }^{(21)}$.

Percebe-se que são inúmeras as barreiras de se conviver com o HIV/aids, muitas são as perdas e as dificuldades encontradas nessa jornada de vida, ou deve-se dizer, de luta pela vida. Essas perdas abrangem diversos aspectos, sejam eles, financeiros, conflitos pessoais, problemas sociais, enfim, as conseqüências da doença são de uma infinidade inquestionável.

A despeito dessas barreiras, todas causam impacto na vida das portadoras do vírus, violando seus direitos e interferindo severamente no modo como elas organizam seu cotidiano e nas possibilidades de serem felizes e gozarem de uma boa qualidade de vida. 


\section{Iminência da morte}

O principal estresse que se submete uma pessoa com aids é o conhecimento e a consciência de ser portador de uma doença letal, com um potencial de rápida deterioração para a morte(21).

A relação entre a doença e a morte parece inevitável, trazendo aspectos relacionados com a vida íntima e com profundas repercussões em sua vida social. A vida é colocada em questionamento para a grande maioria das pessoas que passam a rever suas histórias, seus planos e reavaliar aquilo que consideram essencial.

Mesmo com os avanços no diagnóstico e tratamento, persiste a idéia de aids como morte, seja física ou dos projetos de futuro. Essa idéia estigmatizante pode afastar o portador de HIV/aids e seus cuidadores do usufruto da sua vida pessoal e social, produzindo sofrimento físico e mental ${ }^{(11)}$.

Encontrou-se nas histórias de vida das mulheres a crença de que a morte é uma ameaça constante que deve ser esperada e tolerada o quanto possível, enquanto algumas até pensaram na possibilidade de encurtar essa espera falando em suicídio. $O$ pensamento de morte vem à tona, conforme mostram as falas:

...me senti muito mal quando descobri o meu diagnóstico, naquele momento só passou coisas ruins pela minha cabeça, senti vontade de me matar...está sendo difícil a convivência com a doença...(Rosa)

...no instante do diagnóstico vi o mundo desabar a na minha frente e só pensei em morrer, por duas vezes tentei o suicídio... queria realmente me matar porque a doença não tem cura mesmo, então a morte seria a solução...no momento do diagnóstico me senti um ninguém, como ainda me sinto...(Hortência).

...pensei que eu ia morrer no dia do diagnóstico, receber o diagnóstico positivo foi uma bomba, o mundo desabou, chorei muito, mas agora só posso me conformar não tem mais jeito, pensei que ia morrer no dia do diagnóstico...(Jasmim).

Depreende-se que a sensação de morte esteve presente entre as mulheres. A forma de como a morte foi descrita por elas foi bastante divergente. Algumas relatavam que poderiam morrer ao simples adormecer noturno, enquanto outras pensavam em antecipar esta morte por elas mesmas. Já, uma mulher era enfática ao afirmar que havia tentado o suicídio por duas vezes.

Petúnia diante da confirmação do seu diagnóstico sentiu-se diante da morte. A partir desse período explicitou todas suas vontades, inclusive aquelas consideradas inadequadas para se manter boa saúde.

... foi muito ruim quando soube do diagnóstico, pois tinha muitos sonhos e mudou tudo. No começo eu não tinha mais vida e o restinho que tinha joguei em bebidas, drogas, tudo que não devia fazer...bebi todas, fumei todas...já que estava perto de morrer, pensei em viver tudo que tinha para viver, pois o médico tinha me dado pouco tempo de vida, me senti muito ruim com o diagnóstico e acho que o profissional não deveria ter revelado o verdadeiro resultado...(Petúnia).

Petúnia ainda refere a postura do profissional que mensura os seus dias de vida e não a abordou talvez de forma adequada. A situação de receber um resultado positivo de HIV é um momento de desespero que provoca desestruturação pessoal ${ }^{(22)}$.

Percebe-se que a idéia de fim, de morte, está presente em diferentes momentos e situações na vida dessas muIheres. Os relatos revelam a morte entrelaçada ao HIV/ aids. As mulheres associam a descoberta da soropositividade à perda da vida. $O$ desespero é tão intenso que algumas passam por momentos de insanidade pensando em suicídio. E ainda a denominação da patologia como uma doença incurável, fatal, estigmatizante, contribui para a acentuação destes sentimentos.

A percepção da aids como uma doença que não tem cura e que mata mostra-se muito presente nos estudos. Os pacientes associam a aids à morte, à uma fatalidade que se manifesta de forma rápida e inevitável. Uma vez desenvolvidos os sintomas, o HIV se transforma em aids, minando as possibilidades de tratamento e, conseqüentemente, a esperança de cura ${ }^{(18)}$.

Não é o vírus quem mata, mas a dinâmica que se desencadeia nas profundezas do inconsciente humano, muitas vezes, já muito antes da infecção pelo HIV. Ela é que faz do homem o autor da sua própria morte(23).

Essa autora, ainda refere que se tratarmos um soropositivo ou um paciente de aids, pensando-o como vítima de um vírus devastador, enganamo-nos completamente. Acrescenta que nenhum vírus subsiste à determinação consciente ou inconsciente da vontade humana.

A morte está de certa forma associada à doença. No meio científico muitas vezes comete-se o erro de discutir muito mais a questão da morte pela aids que propriamente a vida com aids ${ }^{(24)}$. Em contrapartida, os portadores do HIV/aids nem sempre se preocupam apenas com a questão da morte, mas sim, buscam incessantemente o direito à vida. Certas situações, como filhos pequenos, projetos de vida em construção, novos relacionamentos, enfim sonhos conduzem esses pacientes a enfrentarem a morte em busca da vida em vida.

O diagnóstico traz uma mensagem de morte, carrega consigo a ameaça dos sonhos desfeitos. $O$ universo de significações e desejos que dava o sentido a vida dessas mulheres passa a ser questionado.

Apreendeu-se nas histórias que as mulheres não conseguem pensar em planos futuros, nem a curto prazo, pois foram também contaminadas pela idéia de morte. Elas vêem distantes e irrealizáveis os tantos sonhos que idealizaram durante suas vidas. 
...meus sonhos eram muitos, inclusive o de ter mais filhos, pois só tenho um, e agora mudou tudo, tinha planos de trabalhar e agora não posso mais trabalhar por causa da perna, mudou tudo, tantos planos que fiz durante anos e nenhum vou realizar...(Jasmim).

Um aspecto importante revelado na história de vida de Jasmim, diz respeito ao desejo de ter filhos e importância que estes têm em sua vida. $O$ desejo de ter filhos é presente para a mulher portadora do HIV/aids, uma vez que na cultura brasileira o mito da maternidade é muito valorizado e profundamente imbricado com a identidade feminina(22).

Diante dos diferentes aspectos observados, percebeuse nesse estudo que, embora a presença da morte tenha sido constatada entre as mulheres, à medida que o tempo passa, a sensação da morte iminente é amenizada.

\section{CONCLUSÃO}

O presente estudo possibilitou inúmeras descobertas, dentre as evidências apreendidas as mulheres reportaram fragilidade diante do diagnóstico, pois ao relem-brarem suas vivências na ocasião da descoberta da doença informam sentimentos como o medo da morte, vergonha, abandono, solidão, tristeza e ansiedade. A revelação do diagnóstico, também foi uma barreira presente da vida de todas as mulheres, situação relacionada ao medo de vivenciar o preconceito e a discriminação por parte das pessoas.

\section{REFERÊNCIAS}

1. Organização das Nações Unidas. Programa Conjunto das Nações Unidas sobre HIV/Aids. EI SIDA: cuidados paliativos. Ginebra; 2001.

2. Julião TC, Aguiar CN, Araújo FM, Silva RM. O cotidiano de mulheres e a prevenção da AIDS. In: Damasceno MMC, Araújo TL, Fernandes AFC. Transtornos vitais no fim do século XX: diabetes mellitus, distúrbios cardiovasculares, câncer, AIDS, tuberculose e hanseníase. Fortaleza: FCPC; 1999. p. 93-102.

3. Associação Brasileira Interdisciplinar de AIDS. Ação Anti AIDS. Rio de Janeiro: Reproarte; 2004.

4. Wood GLB, Haber J. Pesquisa em enfermagem: métodos, avaliação crítica e utilização. Rio de Janeiro: Guanabara Koogan; 2001.

5. Denzin NK, Lincoln YS. Introduction: the discipline and practice of qualitative research. In: Denzin NK, Lincoln YS, editors. Handbook of qualitative research. $2^{\text {nd }}$ ed. Thousand Oaks: Sage; 2000. p. 1-28.

6. Polit DF, Beck CT, Hungler BP. Fundamentos de pesquisa em enfermagem. 5a ed. Porto Alegre: Artes Médicas; 2004.
Evidenciou-se com base na história de vida das portadoras de HIV, que apesar de mais de duas décadas da descoberta da doença as dificuldades enfrentadas pelas mulheres ao vivenciarem sua infecção são evidentes. Houve relatos confirmando sentimentos e experiências de estigma na vida das mulheres infectadas pelo HIV/aids. Situações que permitem indicar que a percepção do enfrentamento da doença é complexa, desgastante além de incessante.

Além da convivência inesperada com a doença, passaram a sentir perdas e dificuldades, como conflitos pessoais e sociais, enfim, estas situações somadas as outras tantas enfrentadas, eram tidas como vultuosas e sem perspectiva de melhora, além da constante relação entre a doença e a morte.

Compreender o enfrentamento das questões relacionadas a aids entre as mulheres é complexo, pois ela carrega consigo o estereótipo de uma doença vergonhosa, fortemente associada a conotações como desvalorização moral e social.

Ressalta-se assim a importância de se promover atendimentos específicos que promovam auto-ajuda para se discutir os múltiplos aspectos implicados no processo de enfrentamento, possibilitando uma maior compreensão sobre a doença, ajudando-as a desmistificar a marca estigmatizante que faz parte da vida dessas pessoas e de seus familiares.
7. Marques S. Cuidadores familiares de idosos: relatos de histórias [dissertação]. Ribeirão Preto: Escola de Enfermagem de Ribeirão Preto, Universidade de São Paulo; 1999.

8. Meihy JCSB. Manual de história oral. São Paulo: Loyola; 1996.

9. Bardin L. Análise de conteúdo. Lisboa: Edições 70; 1977.

10. Conselho Nacional de Saúde. Resolução n. 196, de 10 de outubro de 1996. Dispõe sobre diretrizes e normas regulamentadoras sobre pesquisas envolvendo seres humanos. Bioética. 1996;4(2):15-25.

11. Ayres JRCM, Segurado AAC, Galano E, Marques HHS, França I, Silva $\mathrm{MH}$, et al. Adolescentes e jovens vivendo com HIV/aids: cuidado e promoção da saúde multiprofissional. São Paulo: Office; 2004.

12. Duffy L. Suffering, shame, and silence: the stigma of HIV/AIDS. J Ass Nurs AIDS Care. 2005;16(1):13-20.

13. Christ GH, Siegel K, Moynihan RT. Questões psicossociais: prevenção e tratamento. In: De Vita VT, Hellman S, Rosemberg SA. AIDS/SIDA: etiologia, diagnóstico, tratamento e prevenção. Rio de Janeiro: Revinter; 1991. p. 327-45. 
14. Xavier IM, Leite JL, Braga GM, Nunes PHS. Enfermagem e aids: saber e paradigma. Rev Lat Am Enferm. 1997;5(1): 65-73.

15. Regato VC, Assmar EML. A aids de nossos dias: quem é o responsável? Est Psicol. 2004; 9(1):167-75.

16. Grimberg M. Género y VIH/SIDA: um análisis de los diferenciales de gênero em la experiência de vivir con VIH. Cuad Med Soc. 2000;78(1):41-54.

17. Lent C, Valle A. Aids, sujeito e comunidade. Rio de Janeiro: Programa Nacional de DST/AIDS; 1997.

18. Thiengo MA, Oliveira DC, Rodrigues BMRD. Representações sociais do HIV/AIDS entre adolescentes: implicações para os cuidados de enfermagem. Rev Esc Enferm USP. 2005;39(1):68-76.

19. Gir E. A sexualidade e a mulher portadora do vírus da imunodeficiência humana tipo 1 (HIV-1) [tese]. Ribeirão Preto: Escola de Enfermagem de Ribeirão Preto, Universidade de São Paulo; 1997.
20. Galvão MTG, Cerqueira ATAR, Machado JM. Avaliação da qualidade de vida de mulheres com HIV/aids através do HAT-Qol. Cad Saúde Pública. 2004;20(2):430-7.

21. Flaskerud JH. Aids/Infecção pelo HIV. Rio de Janeiro: MEDSI; 1992. Aspectos psicossociais e neuropsiquiátricos; p. 163-89.

22. Mello MCPF. Contornos femininos da AIDS em São José do Rio Preto: impasses e desafios [dissertação]. Araraquara: Universidade Estadual Paulista; 1999.

23. Paiva V. Em tempos de AIDS. São Paulo: Summus; 1992.

24. Santo PE. O lado obscuro e tentador do sexo. São Paulo: Agora; 2004. 